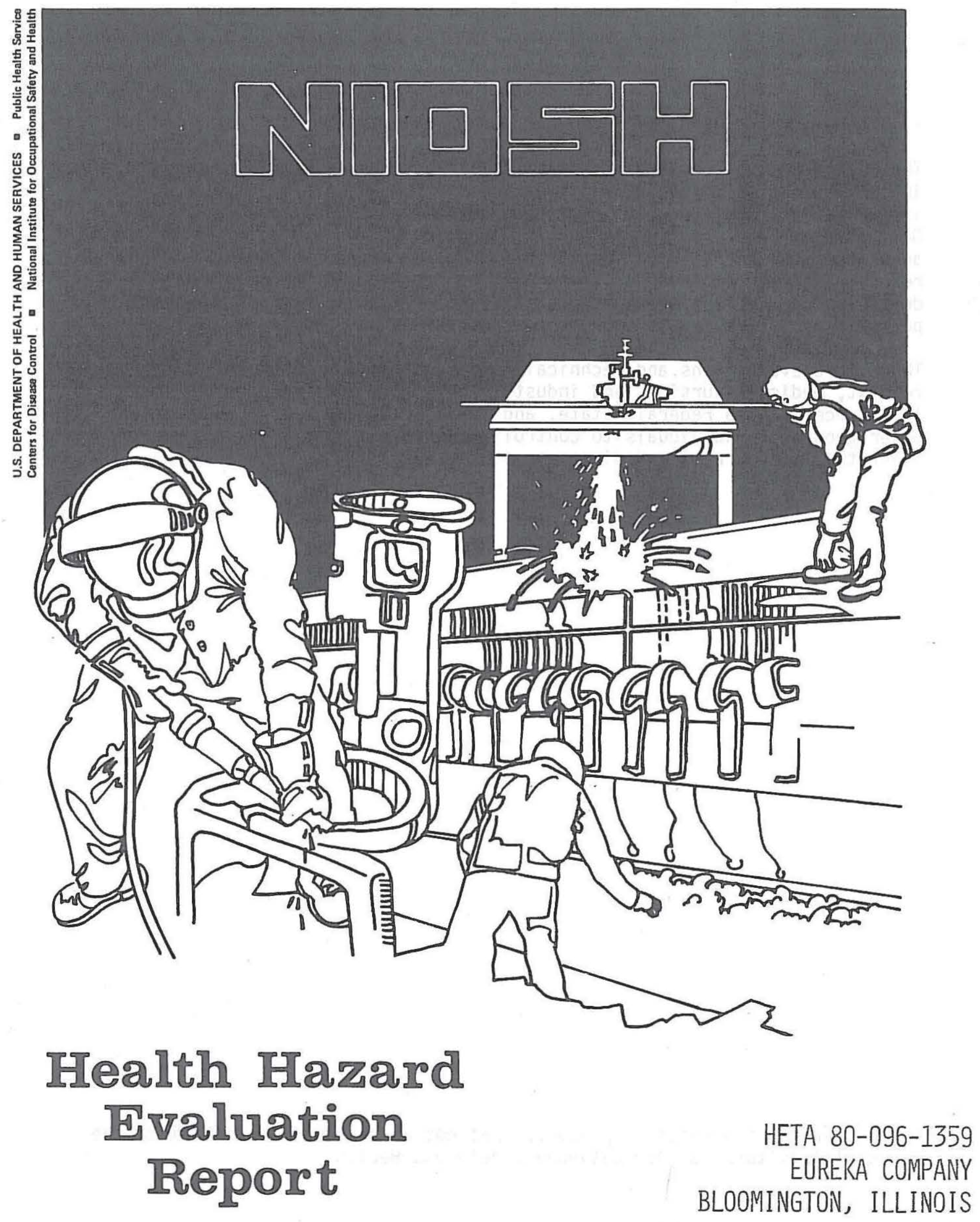




\section{. PREFACE}

The Hazard Evaluations and Technical Assistance Branch of NIOSH conducts field investigations of possible health hazards in the workplace. These investigations are conducted under the authority of Section 20(a)(6) of the Occupational Safety and Health Act of 1970, 29 U.S.C. 669(a)(6) which authorizes the Secretary of Health and Human Services, following a written request from any employer or authorized representative of employees, to determine whether any substance normally found in the place of employment has potentially toxic effects in such concentrations as used or found.

The Hazard Evaluations and Technical Assistance Branch also provides, upon request, medical, nursing, and industrial nygiene technical and consultative assistance (TA) to Federal, state, and local agencies; labor; industry and other groups or individuals to control occupational health hazards and to prevent related trauma and disease.

Mention of company names or products does not constitute endorsement by the National Institute for Occupational Safety and Health. 
1. SUMMARY

Un March 23, 1980, the National Institute for Occupational Safety and Health (NIOSH) was requested to evaluate respiratory and skin problems among employees of the Eureka Company, Bloomington, Illinois. The request particularly concerned those workers employed in Area "W" which manufactured thermal batteries. The workers in this area reported breathing problems, sore throats, and chronic coughs which subside when they leave the area. other complaints included skin rash, nosebleeds, metal taste and green color to the inside of their mouths.

On April 28, 1980, NIOSH investigators responded to the request by conducting an initial survey of the plant. Environmental air samples were collected for magnesium, vanadium, and asbestos and sent to the laboratory for analysis. On succeeding visits medical interviews and physical examinations were conducted by NIOSH physicians; before and after shift, pulmonary function tests administered; spot urine samples collected for vanadium analysis; and pulmonary function reports, as well as chest $x$-rays, were obtained from the company and reviewed by NIOSH.

Short-term personal breathing zone air samples revealed time weighted average (TWA) concentrations of vanadium ranging from 0.10 to 0.19 milligrams per cubic meter of air $\left(\mathrm{mg} / \mathrm{M}^{3}\right)$, with a mean of $0.13 \mathrm{mg} / \mathrm{M}^{3}$. All four samples were above the NIOSH recommended standard for vanadium pentoxide which is a ceiling level of $0.05 \mathrm{mg} / \mathrm{M}^{3}$, averaged over a 15 minute period; but were below the current Occupational Safety and Health Administration (OSHA) ceiling standard $0.5 \mathrm{mg} / \mathrm{M}^{3}$. Personal breathing zone and area air samples for asbestos ranged from 0.01 to 0.53 fibers/cubic centimeter of air (fibers/cc), with a mean of 0.26 fibers/cc. One personal sample was above the NIOSH recommended standard for asbestos of 0.10 fibers greater than 5 microns in length/cc; but all were below the current OSHA standard of 2 fibers/cc as a 8-hour TWA.

A total of 99 persons, all current Eureka Company employees, were medically evaluated. No statistically significant increase in any of the respiratory or mucous membrane symptomatology was found for those workers currently in Area $W$, when compared with a control group of other workers.

On physical examination Area $W$ workers had a higher frequency of skin rashes $(6 / 39)$ than others $(3 / 60) \quad(p=0.082)$. Area $W$ workers were al so more likely to have a green tongue $(8 / 39)$ than workers in other areas $(4 / 60)(p=0.04)$.

Twenty-three Area W workers and 42 workers in other areas had spot urine collected and analyzed for vanadium content. The mean level of urinary vanadium for workers currently in "Area W" was significantly greater than the mean for workers not currently exposed. No difference in the frequency of symptoms or physical findings was evident when the workers with high urinary vanadium were compared with those having low levels.

Pulmonary function tests were performed by NIOSH technicians on 37 Area W workers and 60 workers in other areas. These pre and post-shift pulmonary function tests were normal in 94 workers and none demonstrated evidence of a vanadium induced decrease during the shift.

Review of the Company's medical information revealed a decrease in pulmonary function parameters over the previous 7 years on the part of 11 workers in Area $W$, yet 7 of these returned to normal on follow-up studies despite continued exposure to vanadium. Four workers had pleural thickening and another four were noted to have interstitial disease consistent with asbestosis on review of the radiographs of 68 present and former Area $W$ workers.

Un the basis of the data secured during this Health Hazard Evaluation, NIOSH concluded that a health hazard exists for those workers exposed to asbestos fibers in Area " $W$ " of the Eureka Company Plant in Bloomington, Illinois. Exposure to vanadium dust posed a hazard producing increases in skin rashes and green tongues. Recommendations are included in this report to reduce these exposures, and medically monitor their effects.

KEYWOKUS: SIC 3691 vanadium, asbestos, aerospace, thermal batteries, zirconium. 
Page 2 - Health Hazard Evaluation Report No. 80-096

II. INTRODUCTION

On March 23, 1980, The National Institute for Occupational Safety and Health (NIOSH) was requested to evaluate respiratory and skin problems among employees of the Eureka Company, Bloomington, Illinois. The request particularly concerned those workers employed in Area "W" which manufactured thermal batteries. The request was concerned with potential employee exposure to magnesium, barium chromate, vanadium, lithium chloride, potassium chloride, asbestos, and MICA meta1. The workers in this area reported breathing problems, sore throats, and chronic coughs which subside when they leave the area. Other complaints included skin rash, nosebleeds, metal taste and green color on the inside of their mouths.

On April 28, 1980, NIOSH investigators responded to the request by conducting an initial survey of the plant. An opening conference, attended by management and 1abor, was conducted, followed by a walk-through of Area W. Environmental air samples were collected for vanadium and asbestos and sent to the laboratory for analysis. On June 10,1980 , management and the requestor were sent a report concerning the analysis of these samples. On October 9, 1980, a second survey was conducted at which time the medical aspects of the study were explained to the requestor and management. Confidential medical interviews and examinations were conducted by NIOSH physicians at that time. On November 5 through 71980 , additional confidential medical questionnaires were administered; physical examinations performed; before and after shift, pulmonary function tests administered; spot urine samples collected for vanadium analysis; and pulmonary function reports as well as chest $x$-ray results were obtained from the company. Following the analysis of this data it was decided to secure the $x$-rays taken periodically by the Eureka Company for evaluation by NIOSH B readers. These films were evaluated by NIOSH B readers and a report prepared on March 24, 1982.

\section{BACKGROUND}

\section{A. PLANT PRODUCTION AND WORKFORCE}

The Eureka Company produces vacuum cleaners and thermal batteries. Area W within Department 693 is exclusively concerned with the production of the batteries. This area has been in operation for the last 32 years, with modifications made in the ventilation system in 1979 designed to reduce exposure to vanadium pentoxide dust.

There are 70 production and 20 administrative employees in this area, and 1200 production and 600 administrative employees in the plant as a whole. 
Page 3 - Health Hazard Evaluation Report No. 80-096

\section{B. PROCESS DESCRIPTION AND EMPLOYEE DUTIES}

In the raw material area, zirconium and asbestos are initially scredded and mixed with water to produce a slurry. This slurry is pressed by a hand operated plunger into a sheet which is cut into donut shaped pieces.

In the 10 interconnected dry rooms (4\% relative humidity) of Area $W$, magnesium chromate, potassium chloride, vanadium pentoxide, and $1 \mathrm{ithium}$ chloride are dryed and mixed. A pellet or pill press equipped with local exhaust ventilation automatically presses these components into pellets. The pellets are then rendered to dust again in an enclosed ball mill which has its own exhaust ventilation. The dust is pressed again into pellets and combined with the zirconium/asbestos and nickel coated donuts in layers within a metal case to produce a thermal battery.

Nine employees operate the pill presses, and 60 are employed as assemblers and inspectors. Employees in this area have an average of six to eight years seniority and there are approximately twice as many women as men. The area operates on a two shift basis, with most production on the first shift. The first shift employs 62 workers, while only 8 work second shift. The plant operates five days per week.

\section{ENGINEERING, ADMINISTRATIVE, AND PERSONAL PROTECTIVE CONTROLS}

The dry rooms are enclosed and locally ventilated. Additionally each mixing and milling process has exhaust systems designed to reduce exposure to the dusts.

The following two types of respirators are made available to the employees al though there is no respirator protection program in effect: single use 3-M 8710 TC21C-132 and Norton TC21C-152 cartridge respirators. Employees in this area had pre-employment examinations including a physical, pulmonary function test, and chest x-ray. Area $W$ employees additionaliy received a pulmonary function test and chest x-ray yearly.

IV. MATERIALS AND METHODS

\section{A. ENVIRONMENTAL}

During the initial survey of May 1, 1980, environmental samples were collected to determine airborne concentrations of magnesium, vanadium, and asbestos. Personal samples for vanadium were collected near the breathing zones of four employees, utilizing battery-powered sampling pumps operating at 1.75 liters per minute (Lpm) attached via tygon tubing to 0.8 micron mixed cellulose membrane (AA) filters. These filters were analyzed for magnesium and vanadium by NIOSH Analytical Method P\&CAM 173. Two area samples and 1 personal breathing zone sample were collected for asbestos in the same manner except that the AA filters were sampled "open-faced". These filters were analyzed for asbestos by the procedure outlined in NIOSH Technical Bulletin 77-204. The location and duration of sample collection is provided in Tables 9 \& 10. 
Page 4 - Health Hazard Evaluation Report No. 80-096

B. MEDICAL

1. Questionnaire

On October 9, 1981, a questionnaire was confidentially administered to currently employed Eureka personnel. The questionnaire solicited information on the workers' employment and medical histories, with specific questions concerning mucous membrane irritation and respiratory status modified from the British Medical Research Council's respiratory questionnaire 1 .

2. Urinary Vanadium

On October 9, 1981 urinary spot samples were collected from employees at the time of the physical examination for vanadium analysis. The analysis was performed at the Utah Biomedical Testing Laboratory under contract with NIOSH. The analytic procedure consisted of:

a. Digesting the urine with concentrated nitric acid

b. Extracting the vanadium into chloroform at $\mathrm{pH}$ of 4.0 with 8-quinol inol

c. Destroying the 8-quinolinol-chloroform-vanadium complex with concentrated nitric acid

d. Determining the vanadium concentration by atomic absorption spectrophotometry equipped with electrothermal atomization.

\section{Physical Examination}

On October 9, 1981, NIOSH physicians performed screening physical examinations on Eureka employees. The workers were examined for signs of skin, mucous membrane, or lung disease. Their tongues were also inspected for evidence of green discoloration.

\section{Pulmonary Function}

On November 4 and 5, 1981, before and after shift pulmonary function tests were performed by the employees who had been previously interviewed. Pulmonary Function Testing (spirometry) was conducted by a Certified Pulmonary Function Technician using a Spirotech 200B. Information was recorded concerning height, time since last cigarette, presence of an upper respiratory infection in the last 3 weeks, heavy meal in the last 2 hours, and use of bronchodialator medication.

Company pulmonary function data was abstracted as wel1. These included $F E V_{1}$, FVC, and $F E V_{1} / F V C$ for employees with a potential exposure to asbestos. These examinations had been conducted since 1973. 
Page 5 - Health Hazard Evaluation Report No. 80-096

\section{Radiographic Evaluation}

The chest radiographs evaluated in this study were taken as part of a surveillance program by the Eureka Company for employees potentially exposed to asbestos. The radiographs were submitted by NIOSH to two independent certified B-readers along with 10 NIOSH supplied control films. These films were separately read and then consensus reached between the readers.

\section{EVALUATION CRITERIA}

As a guide to the evaluation of the hazards posed by workplace exposures, NIOSH field staff employ environmental evaluation criteria for assessment of a number of chemical and physical agents. These criteria are intended to suggest levels of exposure to which most workers may be exposed up to 10 hours per day, 40 hours per week for a working 1 ifetime without experiencing adverse health effects. It is, however, important to note that not al1 workers will be protected-from adverse health effects if their exposures are maintained below these levels. A small percentage may experience adverse health effects because of individual susceptibility, a pre-existing medical condition, and/or a hypersensitivity (allergy).

In addition, some hazardous substances may act in combination with other workplace exposures, the general environment, or with medications or personal habits of the worker to produce health effects even if the occupational exposures are controlled at the level set by the evaluation criterion. These combined effects are often not considered in the evaluation criteria. Also, some substances are absorbed by direct contact with the skin and mucous membranes, and thus potentially increase the overall exposure. Finally, evaluation criteria may change over the years as new information on the toxic effects of an agent become available.

The primary sources of environmental evaluation criteria for the workplace are: 1) NIOSH Criteria Documents and recommendations, 2) the American Conference of Governmental Industrial Hygienists' (ACGIH) Threshold Limit Values (TLV's), and 3) the U.S. Department of Labor, Occupational Safety and Health Administration (OSHA) occupational health standards. Often, the NIOSH recommendations and ACGIH TLV's are lower than the corresponding OSHA standards. Both NIOSH recommendations and ACGIH TLV's usually are based on more recent information than are the OSHA standards. In evaluating the exposure levels and the recommendations for reducing these levels found in this report, it should be noted that industry is required by the 0ccupational Safety and Health Act of 1970,29 U.S.C.651, et seq. to meet only those levels specified by an OSHA standard. 
Page 6 - Health Hazard Evaluation Report No. 80-096

A time-weighted average (TẄA) exposure refers to the average airborne concentration of a substance during a normal 8- to 10-hour workday. Some substances have recommended short-term exposure limits or ceiling values which are intended to supplement the TWA where there are recognized toxic effects from high short-term exposures.

\section{A. VANADIUM PENTOXIDE}

\section{Environmental}

Vanadium is a silvery white metal that is frequently used as an alloy to improve the tensile strength of steel, and in the chemical industry as a catalyst. It is distributed sparsely in nature; but it is found in certain plants and lower marine animals, and consequently the main sources are ore and extraction from petroleum residues. Vanadium pentoxide is the most commonly used and studied form.2

The current OSHA standard for vanadium pentoxide fume is a ceiling of 0.5 milligrams per cubic meter of air $\left(\mathrm{mg} / \mathrm{M}^{3}\right)$. NIOSH has recommended that the permissible exposure limit be reduced to a ceiling level of $0.05 \mathrm{mg} / \mathrm{M}^{3}$, averaged over a 15 minute period. 3

\section{Medical}

Vanadium enters the human body primarily through the lungs, and is principally excreted unchanged in the urine. Exposure to high concentrations of vanadium have been found to produce reversible irritative effects principally to the mucous membrane of the eyes, upper respiratory and gastroentestinal system.2

On physical examination frequently hyperplastic changes have been found in the nasal mucosa, rhonchi on chest auscultation, bronchitis on chest $x$-ray. Investigators have additionally reported finding greenish discoloration of the tongue. All of the reported findings of the affect of vanadium appear to be reversible with no significant incidence of long term changes as a result of exposure. To this date, there has been no data that shows its compound to be mutagenic or teratogenic in experimental animals.2

Putmonary function tests of workers exposed to a TWA of 75 micrograms per cubic meter (ug/M3) of $\mathrm{V}_{2} \mathrm{O}_{5}$ in fuel oil ash demonstrated a marked decrease in FVC and FEV 1 over the workday. The subjects' symptoms and clinical signs resolved within 5 days following the end of exposure and the pulmonary function decreases resolved within four weeks. 4 
Page 7 - Health Hazard Evaluation Report No. 80-096

\section{B. ASBESTOS}

\section{Environmenta 5}

Asbestos is a generic term applied to a number of hydrated mineral silicates, including chrysotile, amosite, crocidolite, tremolite, and anthophyllite. Asbestos consists of fibers of varying size, color, and texture. The uses of asbestos are numerous and include thermal and electrical insulation, fire blankets, safety garments, filler for plastics, and roofing materials.

NIOSH recommends that occupational exposure to asbestos be controlled so that workers are not exposed to a workroom air concentration for an 8-hour time-weighted average (TWA) exposure of 0.10 fibers greater than 5 microns in length per cubic centimeter (fibers/cc) and 0.5 fibers/cc for a 15-minute ceiling concentration. The OSHA standard for asbestos for an 8-hour TWA exposure is 2 fibers/cc and a ceiling concentration of 10 fibers/cc. The ACGIH recommends a TLV of 0.10 fibers $/ c c$.

\section{Medical 6}

Asbestos causes a variety of human diseases including asbestosis, cancer of the lungs and digestive tract, and mesothelioma.

Asbestosis is a lung disorder characterized by a diffuse interstitial fibrosis, including pleural changes of fibrosis and calcification. Asbestos bodies may be found in the sputum, and the worker exhibits restrictive pulmonary function. Accompanying clinical changes may include fine rales, finger clubbing, dyspnea, dry cough, and cyanosis. These findings may be delayed in onset $10-15$ years following cessation of exposure.

Bronchogenic carcinoma and mesothelioma of the pleura and peritoneum are ai so caused by asbestos exposure. Excesses of cancer of the stomach, colon, and rectum have been found among asbestos workers. These cancers may occur following a very 1 imited exposure 20 to 30 years earlier.

The NIOSH recommendation and the ACGIH TLV of 0.10 fibers greater than 5 microns in length per cubic centimeter were established to protect against asbestosis and reduce to an acceptably low risk the possibility of the development of neoplasms.

VI. RESULTS

\section{A. ENVIRONMENTAL}

The walk-through evaluation revealed that yellow-green vanadium pentoxide dust was distributed throughout the dry rooms, especially in dry room \#7 where the pill press machines are located. Pill press employees were observed to have vanadium pentoxide dust covering their work aprons. Other employees (assemblers) had the dust $\left(V_{205}\right)$ on their rubber gloves. 
Page 8 - Health Hazard Evaluation Report No. 80-096

Short-term personal breathing zone air samples for vanadium revealed time weighted average (TWA) concentrations of vanadium ranging from 0.10 to $0.13 \mathrm{mg} / \mathrm{M}^{3}$, with a mean of $0.13 \mathrm{mg} / \mathrm{M}^{3}$. (Table 9 ) A11 four samples were above the NIOSH recommended standard for vanadium pentoxide which is a ceiling level of $0.05 \mathrm{mg} / \mathrm{M}^{3}$, averaged over a 15 minute period; but were below the current 0 SHA ceiling standard $0.5 \mathrm{mg} / \mathrm{m}^{3}$. The most significant exposure to $\mathrm{V}_{2} \mathrm{O}_{5}$ occurs when the pill press operator fills metal canisters with powder $\mathrm{V}_{2} \mathrm{O}_{5}$. This operation was inadequately exhausted.

Personal breathing zone and area air samples for asbestos ranged from 0.01 to 0.53 fibers $/ c c$, with a mean of 0.26 fibers $/ c c$. (Table 10) One persona1 sample was above the NIOSH recommended standard for asbestos of 0.10 fibers greater than 5 microns in 1ength/cc; but were below the current OSHA standard of 2 fibers/cc as a 8-hour TWA. The asbestos heat paper tends to disintegrate in the assembly process resulting in worker exposure to asbestos fibers.

\section{B. MEDICAL}

\section{Questionnaire}

A total of 99 persons, all current Eureka Company employees, were evaluated. Table 1 shows demographic data. Occupation was 1isted as "Area W" by 39 of the participants, and other than "Area W" by 60 workers. A total of 84 of the participants were currently or previously employed in "Area W", while only 15 had never been in the area. Average duration of work in "Area $W$ " was 6.2 years.

The ages of study participants ranged from 20 to 63, with a mean age of 43 years. The mean age for workers currently in Area W was 41.6 years and the mean for those currently working in other areas was 44.3 years. Ninety-eight of the workers were white, one Area W worker was black. Seventy-three of the workers were female, 26 of whom worked in Area W. Thirteen of the 26 male workers worked in Area W. Fifty-six were current smokers, 25 working in Area $W$ and 31 in other areas. Nine of the 19 previously smoking workers worked in Area W and 10 did not. Twenty-four workers had never smoked, of which 5 worked in Area W and 19 did not. (Table 1)

Symptoms of nose bleeding, skin rash, metal taste in the mouth, green tongue, dry mouth, cough, phlegm, wheezing, and shortness of breath were reported roughly equally by the employees in Area $W$ and those in other areas. Sinusitis was reported more commonly in those employees not working in Area W. (Table 2)

When these data were stratified for current smoking habits; nosebleeds, sinusitis and shortness of breath was reported more frequently in nonsmokers in areas other than Area $W$ than those nonsmokers in Area $W$. A11 other symptoms amongst nonsmokers occurred in roughly the same frequency for nonsmoking workers in Area $\mathrm{W}$ and elsewhere. Smoking workers at Eureka had approximately the same frequency of symptoms in Area $W$ and elsewhere. (Table 3) 
Nosebleeds and dry mouth were reported more frequently by workers who had ever worked in Area $W$ than those who had never been exposed to this area. No other symptoms differed in frequency between these two groups. (Table 4)

\section{Urinary Vanadium}

Twenty-three Area W workers and 42 workers in other areas had spot urine collected and analyzed for vanadium content. Vanadium was detected in 12 samples $(16 \%)$. Urinary vanadium on spot urine samples varied between $0-85$ micrograms per 1 iter $(\mathrm{ug} / \mathrm{L})$. The mean values for workers currently in "Area W" $(20.65+27 \mathrm{ug} / \mathrm{L}$ was significantly greater than mean urinary vanadium values for workers not currently exposed $(2.73+1.7 \mathrm{ug} / \mathrm{L}$. $[T=4.39$, degrees of freedom $=65, p=0.00002]$

Nine Area W workers had urinary vanadium concentrations above $15 \mathrm{ug} / \mathrm{L}$ while no workers in other areas were noted to have high vanadium content in their urine. (Table 5) No difference in the frequency of symptoms was evident when the workers with high urinary vanadium were compared with those having low levels. (Table 6)

\section{Physical Examination}

Physical examinations were performed by NIOSH physicians on all interviewed workers. These revealed a higher frequency of skin rashes in Area $W$ workers $(6 / 39)$ than in others $(3 / 60)$. Area W workers were also more likely to have a green tongue $(8 / 39)$ than workers in other areas $(4 / 60)$. Wheezing on auscultation of the lungs was found to occur infrequently in both groups. (Table 7) These physical findings were not affected by the levels of urinary vanadium detected. (Table 8)

\section{Pulmonary Function}

Pulmonary function tests were performed by NIOSH technicians on 37 Area $W$ workers and 60 workers in other areas. These pre and post-shift pulmonary function tests were normal, without decreases during the shift in 94 individuals. An obstructive function defect producing an FEV 1 of 1ess than $80 \%$ of the predicted value was found in one worker on both pre- and post-shift PFT's. One worker demonstrated a FVC value of less than $80 \%$ of the predicted on both on pre- and post-shift PFT's indicating a restrictive defect. Additionaliy, one worker, who had not been exposed to vanadium that day, demonstrated a $16 \%$ drop in $\mathrm{FEV}_{1}$ and a $13 \%$ drop in FVC over the work shift.

The Eureka Company has performed surveillance pulmonary function tests (PFT's) on a cohort of 36 "Area W" workers since 1973 at approximately 1-2 yearly intervals. Over the follow-up period, twelve workers had no abnormalities on any of the PFT's performed. Sixteen workers had at least one PFT showing obstructive changes, and 1 worker had at least one PFT with restrictive changes. Seven workers had combined obstructive and restrictive changes seen on PFT's. Eleven workers had a normal first evaluation followed by a change to either obstructive or restrictive change. Mean length of work in Area $W$ before showing obstructive or restrictive change was 5.5 years. Seven of these 11 workers had subsequent normal PFT's which reverted back to normal despite continued exposure to "Area W". 
Page 10 - Health Hazard Evaluation Report No. 80-096

\section{Radiographic Evaluation:}

NIOSH B readers reviewed fi1ms on 68 present and former Area W workers. One hundred and thirty-eight chest radiographs were secured from Eureka that were taken over a 7 year period beginning in October, 1973. Consensus agreement was reached on al1 films. Four workers had pleural thickening agreed to by both $B$ readers on their chest X-rays. Four workers as wel1, were noted to have interstitial disease consistent with asbestosis on their radiographs.

VII. DISCUSSION

\section{A. STUDY BIAS}

The mean age, smoking habits, and race of the group of workers evaluated in Area $W$ was essentially similar to the control group in other areas of the plant. Despite the fact that the percentage of men working in Area W (33\%) was greater than that in the control group (21\%) this comparison would not appear to be effected by any inherent bias.

Due to technical contraints of this study, only approximately $50 \%$ of the current workforce in Area W were interviewed, given physical exams, and had pulmonary function tests. Thirty percent had urine collected for vanadium. While this may introduce certain bias to the data collected, this would be expected to favor findings of health effects in these workers.

This would be expected due to the fact that both union and management were well aware of the study and cooperated fully by informing the employees of the nature of the project. Further, the interviews and testing was done during the workday within the plant and NIOSH investigators visited the plant on multiple occasions. Thus, it would be unlikely that an employee with a health problem in Area W would not have had an opportunity of speaking with the investigators. Since employees with symptoms or health problems thought to be related to Area W work would be more likely than those without to present themselves to the investigators, it is expected that this would increase the finding of an increased frequency of health abnormalities in Area W.

Due to the cross sectional nature of most of these data in this study, a heal thy worker effect can certainly play a role in reducing the number of workers reporting disease in Area W. This effect is produced due to employees transferring from Area $W$ when heal th problems occur. These employees may either remain in the plant and, therefore, elevate the frequency of health problems in our control group or sought employment el sewhere thereby only reducing the frequency of health problems in the Area $\mathrm{W}$ group. There is some indication in the data generated concerning symptoms of former Area W workers that this bias has played a role in this study. 
Page 11 - Health Hazard Evaluation Report No. 80-096

\section{B. SYMPTOMS}

No statistically significant increase in any of the respiratory or mucous membrane symptomatology was found for those workers currently in Area $W$, when compared with the control group. This lack of differential held true when the groups were statified for smoking habits as we11. The analysis of apparent excess of sinusitis by history for those not employed in Area W and of nosebleeds, sinusitis and shortness of breath for nonsmokers not in Area $W$ is beyond the scope of this report.

The statistically significant increase in reporting of nosebleeds and dry mouth amongst employees working currently or in the past in Area W is interesting. In light of the previously mentioned findings concerning persons currently in Area $W$ two explanations may be possible. There may exist another area in the plant that may produce these symptoms of mucous membrane irritation. It is more likely though that employees with symptoms that they relate to Area W may have transferred to other parts of the plant in order to avoid these problems prior to this survey. This transfer pattern was related to the NIOSH investigators by both management and the union during this study. No quantification of this factor was possible.

\section{URINARY VANADIUM}

Normal urinary vanadium values for unexposed individuals have been found to be $<50 \mathrm{ug} / \mathrm{L},<22 \mathrm{ug} / \mathrm{L}$ and $3.5 \mathrm{ug} / \mathrm{L}$ in three separate studies. ${ }^{7}$ The differential findings of increased urinary vanadium in workers in Area $W$ when compared to the control group is an expected result of their obvious exposure. This increase would not seem to be associated with any increased symptomatology or finding on physical exam. Nor would these levels be expected to be associated with any chronic effect not discovered during this cross sectional study.

\section{PHYSICAL EXAMINATION}

Despite the lack of increased symptoms amongst workers in Area $W$ there appears to be a significant increase in skin rashes and green tongues noted on physical exam. As noted above this increase did not appear to be related to the amount of vanadium absorbed by these workers as noted by their urinary excretion.

Green tongues and skin rashes are well known affects of vanadium pentoxide exposure as noted above. They are not known to be associated with any chronic or latent disease but are in themselves evidence of acute vanadium effects.

\section{E. PULMONARY FUNCTION}

Predicted values for normal pulmonary function in the United States corrected for age and height have been established by Knudson. A reading of $80 \%$ or greater for a subject's Forced Vital Capacity (FVC) and One Second Forced Expiratory Volume $\left(F^{2} V_{1}\right)$, when compared with the predicted, is norma1. A ratio of $\mathrm{FEV}_{1} / \mathrm{FVC}$ of $75 \%$ or greater is al so considered norma18. 
Page 12 - Health Hazard Evaluation Report No. 80-096

The findings of one obstructive and one restrictive pattern on pulmonary function tests amongst these workers is well within the expected frequencies in the U.S. population. The single worker with reactive airways whose pulmonary function decrease during her shift would suggest the need for further evaluation of that worker. This evaluation should attempt to assess the factors producing this response.

Since this decrease took place on a day that this employee had no vanadium exposure, the possibility that this environmental cause of bronchospasm could be the causative agent here is unlikely. There are many causes for such a reaction, perhaps the most likely in a cigarette smoker is the possibility that his/her last cigarette was smoked far closer to the test than that in the morning. These possibilities are again beyond the scope of this evaluation of the health effects of work in Area W.

The pathologic decrease in pulmonary function on the part of 11 workers in Area $W$ over the follow-up period of 7 years should be further evaluated by the personal physicians of these individuals. The fact that 7 of these 11 employees had their pulmonary functions return to normal on follow-up studies despite continued exposure to vanadium in Area $W$ mitigates against this as a cause for the decreases.

Since vanadium has been reported to cause pulmonary function changes in previous studies, it would be well to explore this problem in more depth in another study. A longitudinal study with controls for other potential pulmonary toxins and a large population would be necessary to adequately assess whether this substance was capable of producing chronic pulmonary disease. This study is unable to assess this possiblity but has found no severe pathology amongst currently employed workers at this plant.

\section{F. RADIOGRAPHIC EVALUATION}

The chest $X$-rays revealed a prevalence of $5.8 \%$ of pleural thickening in this population of workers. The expected prevalence in the general population is $6.2 \%$, of this group $67 \%$ had histories suggestive of exposure to asbestos. 9 The prevalence of interstitial disease consistent with asbestos in this group of workers should suggest the possiblity of excess exposure to asbestos in this production process. While neither of these findings are definitive for asbestos changes nor greatly above the expected prevalence in the general population in the light of a defined asbestos exposure they are cause for increased vigilance to reduce the amount of fibers absorbed.

VIII. CONCLUSIONS

A. A hazard manifesting as symptoms of mucous membrane and skin irritation was found to exist associated with the dry atmosphere and vanadium dust in Area "W". 
Page 13 - Health Hazard Evaluation Report No. 80-096

B. A potential health hazard due to exposure to asbestos fibers in the raw material and final battery construction areas was found to exist.

C. No evidence was found to indicate that a chronic health hazard due to vanadium existed in Area "W".

\section{RECOMMENDATIONS}

A. The current Medical Surveillance program for all workers exposed to asbestos should be continued and include a pre-employment, yearly, and prior to termination examination comprised of:

1. A medical history eliciting symptomology of respiratory diseases.

2. A physical examination with attention to the Respiratory and Gastroentestinal Systems.

3. A chest X-ray with ob7ique views and interpretation by a certified $B$ reader radiologist.

4. A pulmonary function test including $F E V_{1}$, and FVC.

5. A stool examination for occult blood.

B. Ventilation systems in the areas of grinding or milling dry vanadium should be improved to reduce the amount of vanadium dust escaping into the general environment.

C. Improvement in housekeeping measures to reduce the amount of vanadium dust continually recirculated in the environment.

D. Cortinuation of the company policy of removing those individuals found to be hypersensitive to vanadium dust to other non exposed areas.

\section{$X$. REFERENCES}

1. Bouhuys, A. Breathing: Physiology, Environment, and Lung Disease New York: Grune and Stratton; 1974: 307-13

2. Criteria for a Recommended Standard for 0ccupational Exposure to Vanadium OHHS(NIOSH) PubTication 77-222, 1977

3. Occupational Health Guidelines for Chemical Hazards NIOSH/OSHA, U.S. Dept. of Labor, DHHS(NIOSH) PubTication 81-123, 1981, P. 29

4. Lees, REM. Changes in Lung Function after Exposure Vanadium Compounds in Fuel 0il Ash British Journal of Industrial Medicine, 37:253-256, 1980

5. Occupational Health Guidelines for Chemical Hazards NIOSH/OSHA, U.S. Dept. of Labor, DHHS(NIOSH) PubTication 81-123, 1981, P. 5

6. Proctor, N.H. and Hughes, J.P., Chemical Hazards of the Workplace, J.P. Lippincott Company, Philadelphia, 1978, pp. 112-113. 
Page 14 - Health Hazard Evaluation Report No. 80-096

7. Berman, E. Toxic Metals and Their Analysis Heyden and Son, 1980, Philadelphia, PA, p. 224

8. Knudson, R.J., et. al. Maximal Expiratory Flow Volume Curve, American Review of Respiratory Disease 113:587-600, 1976.

9. Albelda, S.M. et. a1. Pleural Thickening: Its Significance and Relationship to Asbestos Dust Exposure American Review of Respiratory Disease 126:621-624, 1982

XI . AUTHORSHIP AND ACKNOWLEDGEMENTS

Report Prepared by:

Environmental Evaluation:

Originating office:
Peter Orris, MD, MPH

Medical officer

NIOSH - Region V

Chicago, Illinois

James Cone, MD, MPH

Medical Officer

NIOSH - HETAB

Cincinnatti, Ohio

Emanuel Dozier, MD, MPH

Resident

Occupational Medicine

Cook County Hospital

Chicago, Illinois

Shawn McQuitkin, IH

Industrial Hygienist

NIOSH - Region $V$

Chicago, Illinois

Division of Surveillance, Hazard Evaluations \& Field Studies

Hazard Evaluation and Technical Assistance

Branch

Cincinnati, Ohio 
Page 15 - Health Hazard Evaluation Report No. 80-096

XII. DISTRIBUTION AND AVAILABILTIY OF THE REPORT

Copies of this Determination Report are currently available upon request from NIOSH, Division of Standards Development and Technology Transfer, Information Resources and Dissemination Section, 4676 Columbia Parkway, Cincinnati, Ohio 45226. After 90 days the report will be available through the National Technical Information Services (NTIS), Springfield, Virginia. Information regarding its availability through NTIS can be obtained from NIOSH publications office at the Cincinnati address. Copies of this report have been sent to the following:

A. Eureka Company, Inc.

B. International Association of Machinists, AFL-CIO

C. U.S. Department of Labor, OSHA - Region V

D. NIOSH Regional Offices/Divisions

For the purposes of informing the affected employees, copies of the report should be posted in a prominent place accessible to the employees, for a period of 30 calendar days. 
TABLE 1

DESCRIPTIVE DATA

\begin{tabular}{|c|c|c|c|}
\hline \multirow[t]{2}{*}{ CHARACTERISTIC } & \multicolumn{2}{|c|}{ CURRENT WORK SITE } & \multirow[b]{2}{*}{ Total } \\
\hline & Area W & Other & \\
\hline Production Workers & 77 & 1200 & 1277 \\
\hline Workers Interviewed & 39 & $60 *$ & 99 \\
\hline Age & $\begin{array}{l}24-61 \text { yrs. } \\
\bar{M}=41.6\end{array}$ & $\begin{array}{l}20-63 \text { yrs. } \\
\bar{M}=44.3\end{array}$ & $\begin{array}{l}20-63 \text { yrs. } \\
\bar{M}=43\end{array}$ \\
\hline $\begin{array}{l}\text { Race } \\
\text { White } \\
\text { Black }\end{array}$ & $\begin{array}{r}38 \\
1\end{array}$ & 60 & $\begin{array}{r}98 \\
1\end{array}$ \\
\hline $\begin{array}{l}\text { Sex } \\
\text { Male } \\
\text { Female }\end{array}$ & $\begin{array}{l}13 \\
26\end{array}$ & $\begin{array}{l}13 \\
47\end{array}$ & $\begin{array}{l}26 \\
73\end{array}$ \\
\hline Cigarette Smoking & & & \\
\hline $\begin{array}{l}\text { Current } \\
\text { Past } \\
\text { Never }\end{array}$ & $\begin{array}{r}25 \\
9 \\
5\end{array}$ & $\begin{array}{l}31 \\
10 \\
19\end{array}$ & $\begin{array}{l}56 \\
19 \\
24\end{array}$ \\
\hline $\begin{array}{l}\text { Workers with NIOSH } \\
\text { Physical Examinations }\end{array}$ & 39 & 60 & 99 \\
\hline $\begin{array}{c}\text { Workers With NIOSH Pulmonary } \\
\text { Function Tests }\end{array}$ & 37 & 60 & 97 \\
\hline $\begin{array}{l}\text { Workers with NIOSH Urinary } \\
\qquad V_{2} \mathrm{O}_{5} \text { Samples }\end{array}$ & 23 & 42 & 65 \\
\hline $\begin{array}{r}\text { Workers with NIOSH B-Reader } \\
\text { Reviewed Chest X-rays }\end{array}$ & & & 68 \\
\hline
\end{tabular}


Table 2

SYMPTOMS REPORTED VS. CURRENT WORK AREA

$\begin{array}{lcc}\text { SYMPTOM } & \begin{array}{c}\text { AREA W. } \\ \mathrm{N}=39\end{array} & \begin{array}{c}\text { OTHER AREA } \\ \mathrm{N}=60\end{array} \\ \text { Nosebleed } & 14 & 21 \\ \text { Sinusitis* } & 11 & 33 \\ \text { Skin Rash } & 9 & 18 \\ \text { Metal Taste } & 2 & 6 \\ \text { Green Tongue } & 2 & 4 \\ \text { Dry Mouth } & 22 & 27 \\ \text { Cough } & 14 & 23 \\ \text { Phiegm } & 15 & 23 \\ \text { Wheezing } & 18 & 30 \\ \text { Shortness 0f Breath } & 19 & 37 \\ & \\ \text { *Statistical Ty significant increase in frequency of workers with sinusitis who } \\ \text { are working in areas other than area W on analysis by Chi-square at } \mathrm{p}=.009 .\end{array}$


Table 3

SYMPTOMS REPORTED VS. CURRENT WORK AREA

STRATIFIED FOR CURRENT SMOKING HABITS

\begin{tabular}{|c|c|c|c|c|}
\hline \multirow[b]{2}{*}{ SYMPTOM } & \multicolumn{2}{|c|}{ SMOKERS } & \multicolumn{2}{|c|}{ NONSMOKERS } \\
\hline & $\begin{array}{l}\text { AREA W. } \\
\mathrm{N}=25\end{array}$ & $\begin{array}{c}\text { OTHER AREA } \\
\mathrm{N}=31\end{array}$ & $\begin{array}{c}\text { AREA } W . \\
N=14\end{array}$ & $\begin{array}{c}\text { OTHER AREA } \\
N=29\end{array}$ \\
\hline Nosebleed & 10 & 7 & 4 & $14 \leftleftarrows$ \\
\hline Sinusitis & 8 & 15 & 3 & $18 *$ \\
\hline Skin Rash & 5 & 11 & 4 & 7 \\
\hline Metal Taste & 0 & 3 & 2 & 3 \\
\hline Green Tongue & 0 & 1 & 2 & 3 \\
\hline Dry Mouth & 14 & 15 & 8 & 12 \\
\hline Cough & 12 & 16 & 2 & 7 \\
\hline Phlegm & 12 & 17 & 3 & 6 \\
\hline Wheezing & 16 & 21 & 2 & 9 \\
\hline Shortness of Breath & 14 & 19 & 5 & $18+$ \\
\hline \multicolumn{5}{|c|}{$\begin{array}{l}\text { * Statistically significant increase in frequency of workers with sinusitis or } \\
\text { nosebleeds who are currently in areas other than area } W \text { on analysis by } \\
\text { Chi-square or Fishers Exact tests at } p=0.02 \text { or less. } \\
+ \text { Increase in frequency of workers with shortness of breath who are in areas } \\
\text { other than area } W \text { at } p=0.061\end{array}$} \\
\hline
\end{tabular}


Table 4

RESPIRATORY SYMPTOMS VS. CURRENT OR PAST WORK AREA

\begin{tabular}{|c|c|}
\hline SYMPTOM & $\begin{array}{c}\text { NEVER IN AREA W } \\
N=15\end{array}$ \\
\hline Nosebleed & $33 t$ \\
\hline Sinusitis & 36 \\
\hline Skin Rash & 22 \\
\hline Metal Taste & 15 \\
\hline Green Tongue & 15 \\
\hline Dry Mouth & $46^{*}$ \\
\hline Cough & 33 \\
\hline Phlegm & 33 \\
\hline Wheezing & 42 \\
\hline Shortness of Breath & . \\
\hline \multicolumn{2}{|c|}{$\begin{array}{l}\text { I Increase in frequency of workers with nosebleeds who are now working or have } \\
\text { worked in the past in Area } W \text { at } p=0.054 \\
\text { * Statistically significant increase in the frequency of workers with dry mouth } \\
\text { who are now working or have worked in Area } W \text { on analysis by Chi-square at } \\
p=.014 \text {. }\end{array}$} \\
\hline
\end{tabular}


Table 5

URINARY VANADIUM VS. CURRENT WORK AREA

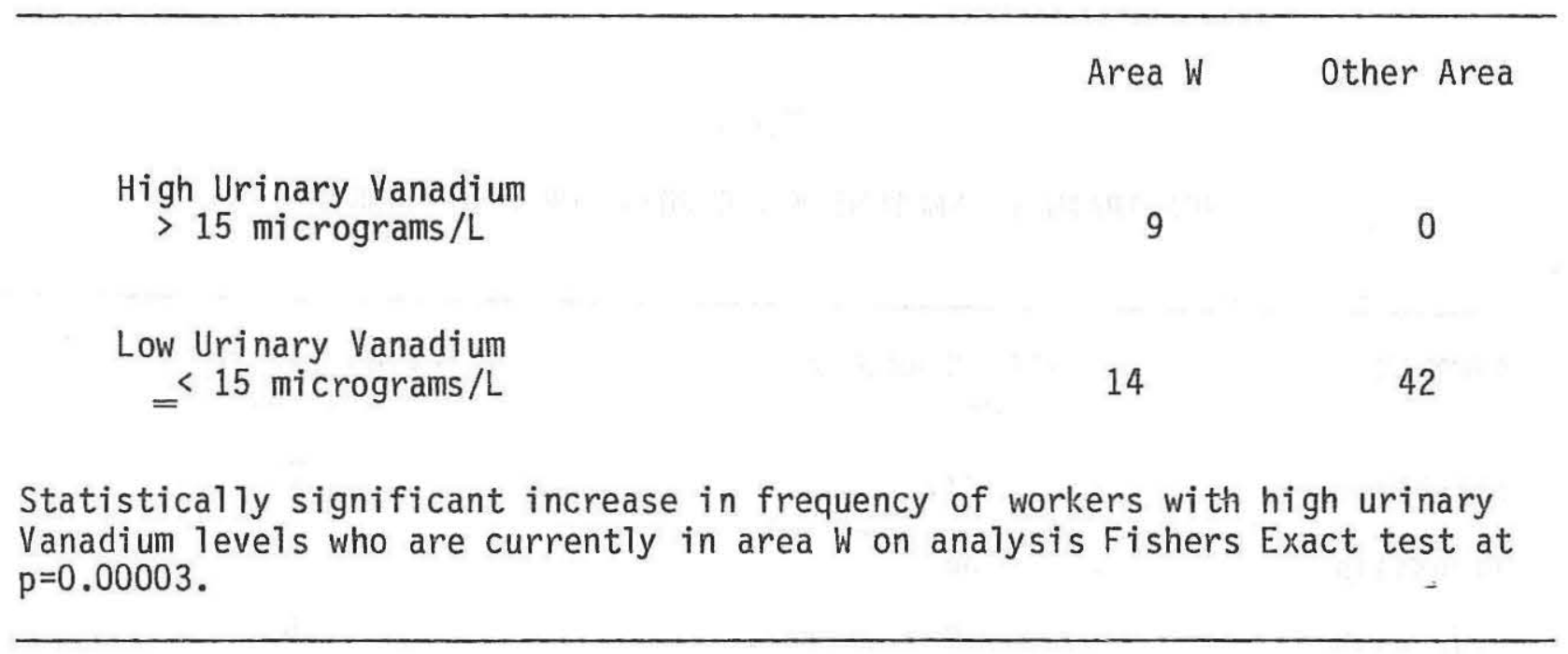

Table 6

SYMPTOMS REPORTED VS. URINARY VANADIUM

\begin{tabular}{lcc}
\hline SYMPTOM & $\begin{array}{c}\text { High } \\
\frac{\text { Urine V }}{N=9}\end{array}$ & $\begin{array}{c}\text { Low urine } \\
\frac{\text { Vanadium }}{N=56}\end{array}$ \\
Nosebleed & 3 & 21 \\
Sinusitis & 2 & 29 \\
Skin Rash & 3 & 17 \\
Metal Taste & 1 & 5 \\
Green Tongue & 1 & 3 \\
Dry Mouth & 5 & 29 \\
Cough & 3 & 25 \\
Phlegm & 3 & 23 \\
Wheezing & 3 & 30 \\
Shortness of Breath & 5 & 35 \\
\end{tabular}




\section{TABLE 7}

PHYSICAL EXAMINATION VS. CURRRENT WORK AREA

PHYSICAL FINDING

Skin Rash

Green Tongue

Wheezing
WORKERS IN AREA W $\mathrm{N}=39$

6

8

2
WORKERS IN OTHER AREAS $\mathrm{N}=60$

$3+$

4 *

2

t Increase in the frequency of workers with skin rashes who are currently in area $W$ on analysis Fishers Exact test at $p=0.082$.

* Statistically significant increase in frequency of workers with green tongues who are currently in area $W$ on analysis Fishers Exact test at $p=0.04$.

TABLE 8

PHYSICAL EXAMINATION VS. URINARY VANADIUM CONCENTRATION

PHYSICAL FINDING

Skin Rash

Green Tongue

Wheezing
WORKERS WITH HIGH URINARY VANADIUM $\mathrm{N}=9$

3

1

3
WORKERS WITH LOW URINARY VANADIUM $\mathrm{N}=55$

16

3

30 
Table 9

Results of Short-Term Breathing Zone Sampling for Vanadium

(Samples collected May 1, 1980)

\begin{tabular}{|c|c|c|c|}
\hline Job Title & Location & Sample Time & Vanadium Conc \\
\hline Press operator & Dry Room \#7 & 49 minutes & $0.19 \mathrm{mg} / \mathrm{M}^{3}$ \\
\hline Press operator & Dry Room \#7 & 15 minutes & $0.13 \mathrm{mg} / \mathrm{M}^{3}$ \\
\hline Press operator & Dry Room \#7 & 15 minutes & $0.10 \mathrm{mg} / \mathrm{M}^{3}$ \\
\hline Press operator & Dry Room \#7 & 15 minutes & $0.10 \mathrm{mg} / \mathrm{M}^{3}$ \\
\hline
\end{tabular}

Table 10

Results of Environmental Samples Collected for Asbestos

(Samples collected May 1, 1980)

\begin{tabular}{|c|c|c|c|}
\hline Sample Type & Job Title/Location & Sample Time & $\begin{array}{l}\text { Concentration } \\
\text { Asbestos }\end{array}$ \\
\hline Area & Receiving & 154 minutes & 0.01 fibers $/ c c$ \\
\hline Personal & Bristow/Dry Room 10 & 127 minutes & 0.53 fibers $/ c c$ \\
\hline Area & Dry Room \#10 & 147 minutes & 0.24 fibers $/ c c$ \\
\hline
\end{tabular}


DEPARTMENT OF HEALTH AND HUMAN SERVICES

PUBLIC HEALTH SERVICE

CENTERS FOR DISEASE CONTROL

NATIONAL INSTITUTE FOR OCCUPATIONAL SAFETY AND HEALTH

ROBERT A. TAFT LABORATORIES

4676 COLUMBIA PARKWAY, CINCINNATI, OHIO 45226

OFFICIAL BUSINESS

PENALTY FOR PAIVATE USE. $\$ 300$

\section{Third Class Mail}

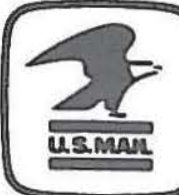

POSTAGE AND FEES PAID U.S. DEPARTMENT OF HHS HHS 396 